\title{
ВмJ Global Health Responding to the COVID-19 second wave in Thailand by diversifying and adapting lessons from the first wave
}

\author{
Nattadhanai Rajatanavin (D) ,' Titiporn Tuangratananon, ${ }^{1,2}$ \\ Rapeepong Suphanchaimat, ${ }^{1,3}$ Viroj Tangcharoensathien ${ }^{1}$
}

\begin{abstract}
To cite: Rajatanavin N, Tuangratananon $\mathrm{T}$, Suphanchaimat $\mathrm{R}$, et al. Responding to the COVID-19 second wave in Thailand by diversifying and adapting lessons from the first wave. BMJ Global Health 2021;6:e006178. doi:10.1136/ bmjgh-2021-006178
\end{abstract}

Handling editor Seye Abimbola

Received 2 May 2021

Accepted 8 July 2021

Check for updates

(c) Author(s) (or their employer(s)) 2021. Re-use permitted under CC BY-NC. No commercial re-use. See rights and permissions. Published by BMJ.

${ }^{1}$ International Health Policy Program, Ministry of Public Health, Nonthaburi, Thailand ${ }^{2}$ Bureau of Health Promotion, Department of Health, Ministry of Public Health, Nonthaburi, Thailand

${ }^{3}$ Bureau of Epidemiology, Department of Disease Control, Ministry of Public Health, Nonthaburi, Thailand

Correspondence to Dr Nattadhanai Rajatanavin; nattadhanai@ihpp.thaigov.net

\section{ABSTRACT}

Thailand's first wave of COVID-19 in March 2020 was triggered from boxing events and nightclubs in Bangkok, which spread to 68 provinces. The nation responded rapidly with strong public health and social measures on 26 March 2020. Contact tracing was performed by over 1000 surveillance and rapid response teams with support from 1.1 million village health volunteers to identify, isolate and quarantine cases.

Thailand implemented social measures in April 2020 including a full-scale national lockdown, curfews and 14-day mandatory quarantine for international travellers. With a strong health system infrastructure, people's adherence to social measures and a whole-of-government approach, the first wave recorded only 3042 cases and 57 deaths with $1.46 \%$ case fatality rate. Economic activities were resumed on 1 May 2020 until the end of the year. On 17 December 2020, a second wave was carried by undocumented migrants who were not captured by the quarantine system. As the total lockdown earlier led to serious negative economic impact, the government employed a targeted strategy, locking down specific areas and employing active case finding. Essential resources including case finding teams, clinicians and medicine were mobilised.

With synergistic multisectoral efforts involving health, nonhealth and private sector, the outbreak was contained in February 2021. Total cases were seven times higher than the first wave, however, early admission and treatment resulted in $0.11 \%$ case fatality rate. In conclusion, experiences of responding to the first wave informed the second wave response with targeted locking down of affected localities and active case findings in affected sites.

\section{INTRODUCTION}

Thailand responded effectively to the first wave of COVID-19, which began in March 2020. The epidemic was triggered by clusters of cases related to events at the boxing stadium and nightclubs in Bangkok and which later spread to 68 provinces. ${ }^{1}$ Muslim pilgrims returning from Malaysia and Indonesia also spread the virus to various southern provinces. ${ }^{23}$ The peak of daily cases in March

\section{Summary box}

Public health (test, trace and quarantine) and social measures (face masks, physical distancing, hand hygiene, generalised restriction of travelling) were fully applied in the first wave of COVID-19 with favourable results; there was no local transmission after 25 May 2020 until December 2020.

- Public health measures were diversified to include active case findings and five-sample pooled saliva tests to save costs on a very large number of daily tests.

- Migrant health workers and volunteers were deployed to garner support for public health and social measures.

- Social measures, notably face masks, physical distancing and hand hygiene continued, while selective and targeted restrictions were applied through the provinces with differentiated interventions.

was under 200; but by 25 May 2020, there were 3042 cumulative cases and 57 deaths. Epidemiology evidence reported no local transmission after 25 May as all subsequent cases were diagnosed in international travellers, both Thai and non-Thai, at the state quarantine systems.

The second wave was triggered by some Thai workers who, having worked in an entertainment complex in a northern state of Myanmar, entered Thailand illegally and were not captured by state quarantine. They carried the virus and spread it to several northern provinces in Thailand. In addition, a large number of migrant workers who carried the virus travelled directly and illegally from Myanmar and worked in factories and seafood markets in Samut Sakhon province, a neighbouring province of Bangkok (see figure 1). Infection among workers in this seafood market, the largest supplier to the whole country, triggered local transmission to more than half of the provinces nationwide. Simultaneously, a few large clusters spread 


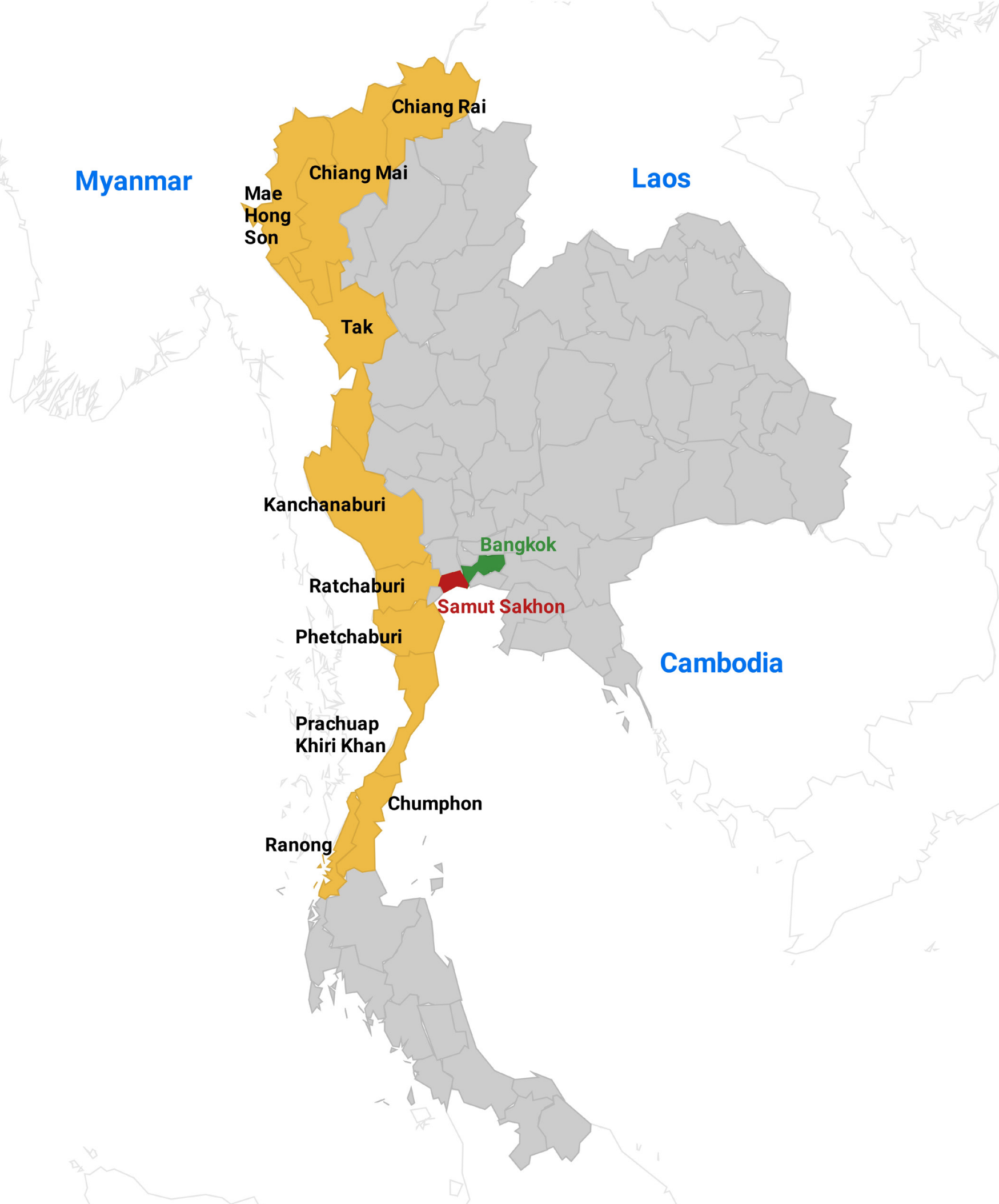

Figure 1 Map of Thailand borders and Samut Sakhon province. The yellow shade are 10 provinces with $2400 \mathrm{~km}$ land border from Myanmar.

from illegal casino sites in three eastern provinces. Index cases suspected undocumented Cambodian migrants working in these sites.
The second wave was far greater and more complex than the first wave. With 21584 additional cases in 2.5 months (between 18 December 2020 and 27 February 
2021), the caseload was seven times than that of the 3042 cases during the first wave. By the last week of February 2021, daily cases decreased to less than 100 , which demonstrates that the situation is gradually under control.

This paper analyses how drawing on experiences of public health and social measures and governance responses during the first wave informed the second wave response, and identifies lessons and gaps for further improvement. We used secondary data from various sources such as official reports, surveys, secondary data analysis and minutes of the Ministry of Public HealthEmergency Operation Centre (MOPH-EOC), for which the authors have had direct observations in all EOC meetings since May 2020.

\section{PUBLIC HEALTH AND SOCIAL MEASURES USED IN THE FIRST WAVE \\ Public health measures}

During the first wave, conventional public health measures were applied including the following: identifying the index cases using case definitions produced and updated regularly by the MOPH; tracing and testing of all highrisk contacts; treatment of all cases in hospitals; and isolation in quarantine sites at least 14 days from the onset of symptoms in order to prevent transmission. ${ }^{4}$ All these were enforced through the 2015 Communicable Diseases Act.

As the laboratory is a necessity for case detection, the MOPH understood that limited laboratory capacity was a major barrier to pandemic containment. Real-time PCR
(RT-PCR) laboratory capacity was scaled up nationwide, from 80 certified laboratories in April 2020 to 110 in June 2020 and 230 (154 public and 76 private laboratories) in October 2020 covering all 77 provinces; all provided a turnaround time of 24 hours for results. ${ }^{5}$ Installation of negative pressure intensive care units and the stockpiling of personal protective equipment and medicines were key preparedness measures in this wave for future unforeseen large outbreaks.

Containing the outbreak also relies on the key role of more than 1000 surveillance and rapid response team (SRRT) members comprising public health nurses and officers, with epidemiologists in some teams. ${ }^{6}$ SRRT are stationed at provincial health offices and district hospitals and are networked with subdistrict health centres. In Bangkok, the SSRT are linked to the Department of Diseases Control and Bangkok Metropolitan Administration. At the subdistrict level, more than 1 million village health volunteers (VHVs) and staff from subdistrict health centres supported the SRRT. VHVs helped in assessing villagers' risk of exposure to infection and liaised with the subdistrict health centres. ${ }^{7}$ The cost of lab testing and treatment was fully subsidised by the government in all cases regardless of nationality (see figure 2).

\section{Social measures}

In the absence of global guidelines on what constitutes effective social measures, the government aimed to minimise droplet transmission through the use of face masks, hand hygiene, physical distancing and discouragement

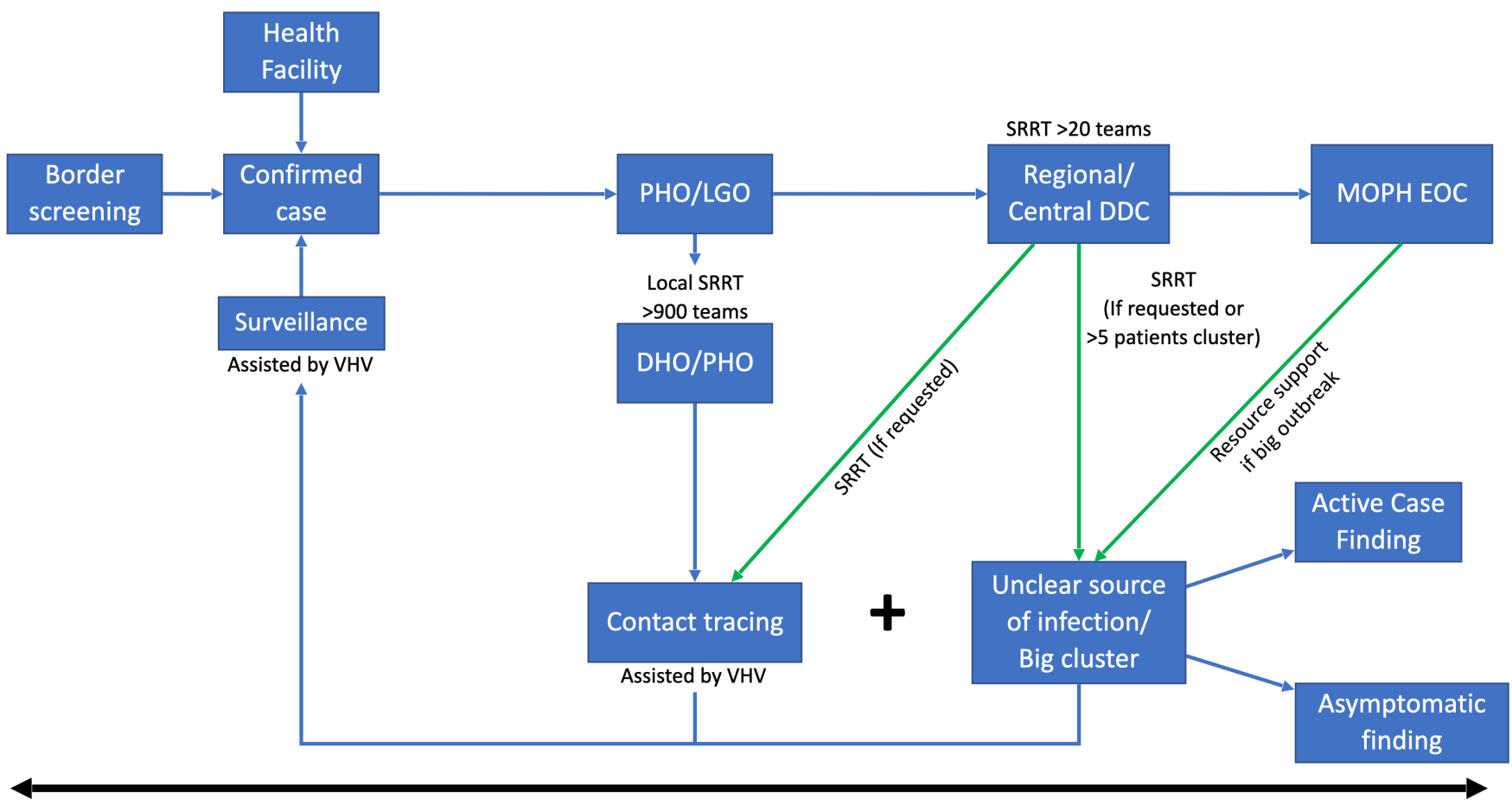

Electronic Database

Figure 2 Network diagram of surveillance and rapid response teams (SRRTs) and village health volunteers (VHVs). DDC, Department of Disease Control; DHO, District Health Office; EOC, Emergency Operation Center; LGO, Local Government Office; MOPH, Ministry of Public Health; PHO, Provincial Health Office. 
of social gatherings. The government declared and enforced a State of Emergency Decree on 26 March 2020 and curfews between 22:00 and 04:00 on 2 April 2020. Among other measures, the government also advocated, although did not make mandatory, a 'stay home' policy for the whole of April 2020, cancelled national holidays to prevent massive social gatherings and domestic travel, and imposed school closures and restrictions of access to all public spaces except the essential. All international flights were suspended from 4 April 2020; only emergency or authorised flights were permitted.

All social measures were applied throughout the country by a single command centre, the Centre for COVID-19 Situation Administration (CCSA), led by the prime minister. The CCSA is a whole-of-government effort. The centre monitored and assessed the situation, then formulated national policies and actions. Coherent policy and daily updates prevented confusion and anxiety in the population.

All people including foreign residents were asked to wear face masks (although this was not mandatory), to keep a physical distance of more than $2 \mathrm{~m}$ and to adhere to hand hygiene. The coverage of face mask use was high well before evidence of its effectiveness. ${ }^{8}$ The population's adherence to social measures through regular surveys was reported to the CCSA.

The April 2020 weekly online surveys were promoted through social media, with 100000 respondents, although samples were dominated by responses from Bangkok residents and the highly educated. Other online nationwide surveys (weekly, fortnightly or monthly depending on the epidemic context) took place between May 2020 and February 2021 and were conducted through VHVs reaching out to households, with 50000-60000 respondents per round. The data were collected using Google forms accessed by a QR code or URL link through mobile phones. Although respondents were numerous, $70 \%$ were women and there was potential positive bias in the self-reporting of personal protection such as use of face masks. Misinterpretation of the questions and survey fatigue were also key limitations (see figure 3).

Population compliance with the social measures was also monitored through Google mobility data. ${ }^{9}$ There was a significant reduction of population mobility in April 2020 to major transit coach and railway stations $(-60 \%)$ and workplaces $(-30 \%)$, and a moderate increase in people staying in their residential areas $(+20 \%)$ (see figure 4).

Combined public health and social measures introduced in the early phase of the epidemic was effective with no local transmissions occurring since 25 May 2020. The government monitored closely any infections brought in by international travellers, including nationals and non-nationals, through state quarantine, mandatory for all travellers entering Thailand through air, land and sea. Daily cases were under 10 and sentinel surveillance conducted in May-June revealed no new cases. ${ }^{10}$ In July 2020, the improved epidemiological situation and need to reduce the negative economic impact from travel restrictions triggered the phasing out of certain social measures and the resumption of economic activities. ${ }^{11}$ In parallel, people lowered their personal protection measures and increased their mobility.

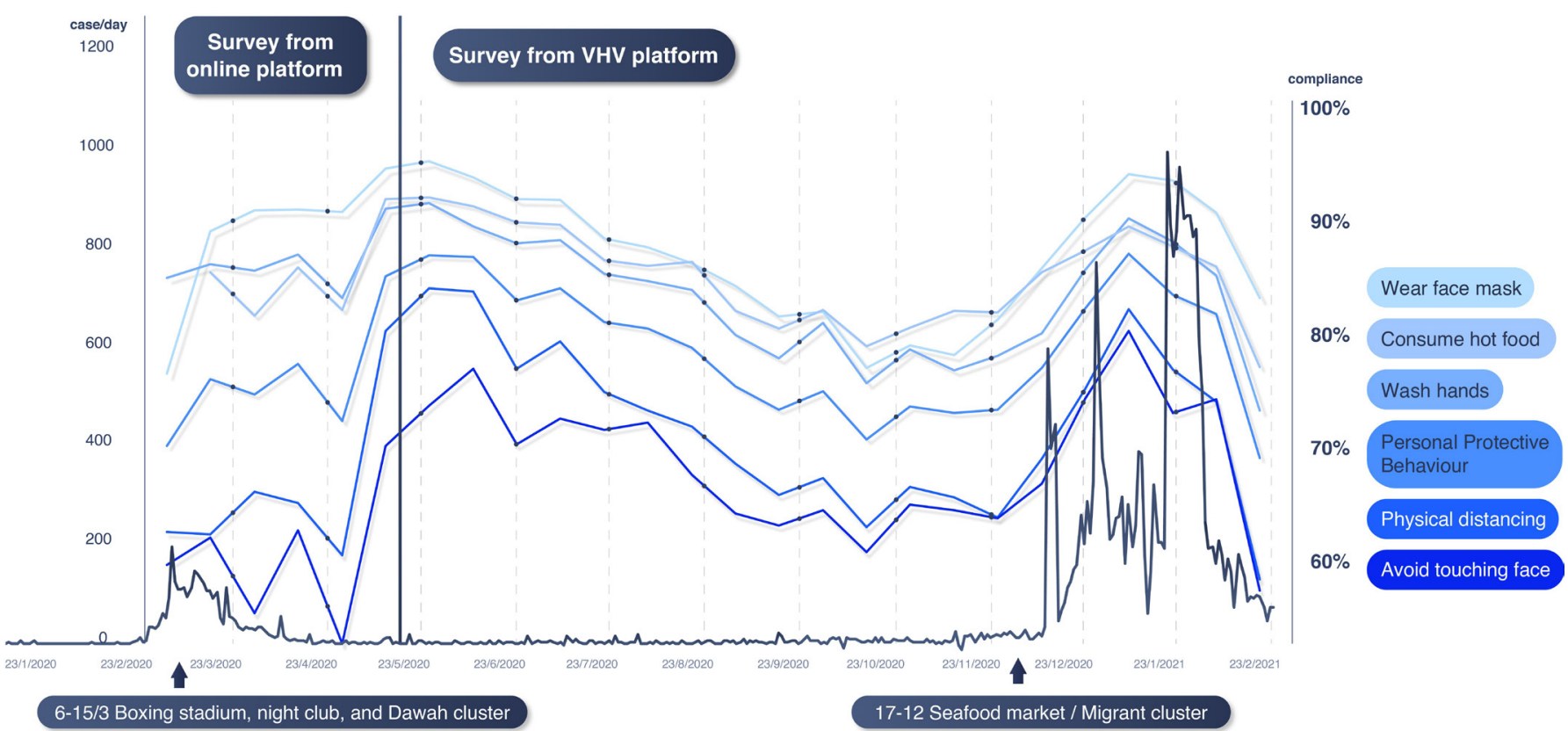

Figure 3 Daily cases and personal protective behaviours trend; 1 April 2020-28 February 2021. *The result from 1 to 30 April 2020 was from online platform, while onwards was derived from the VHV-assisted platform. VHV, village health volunteer. 


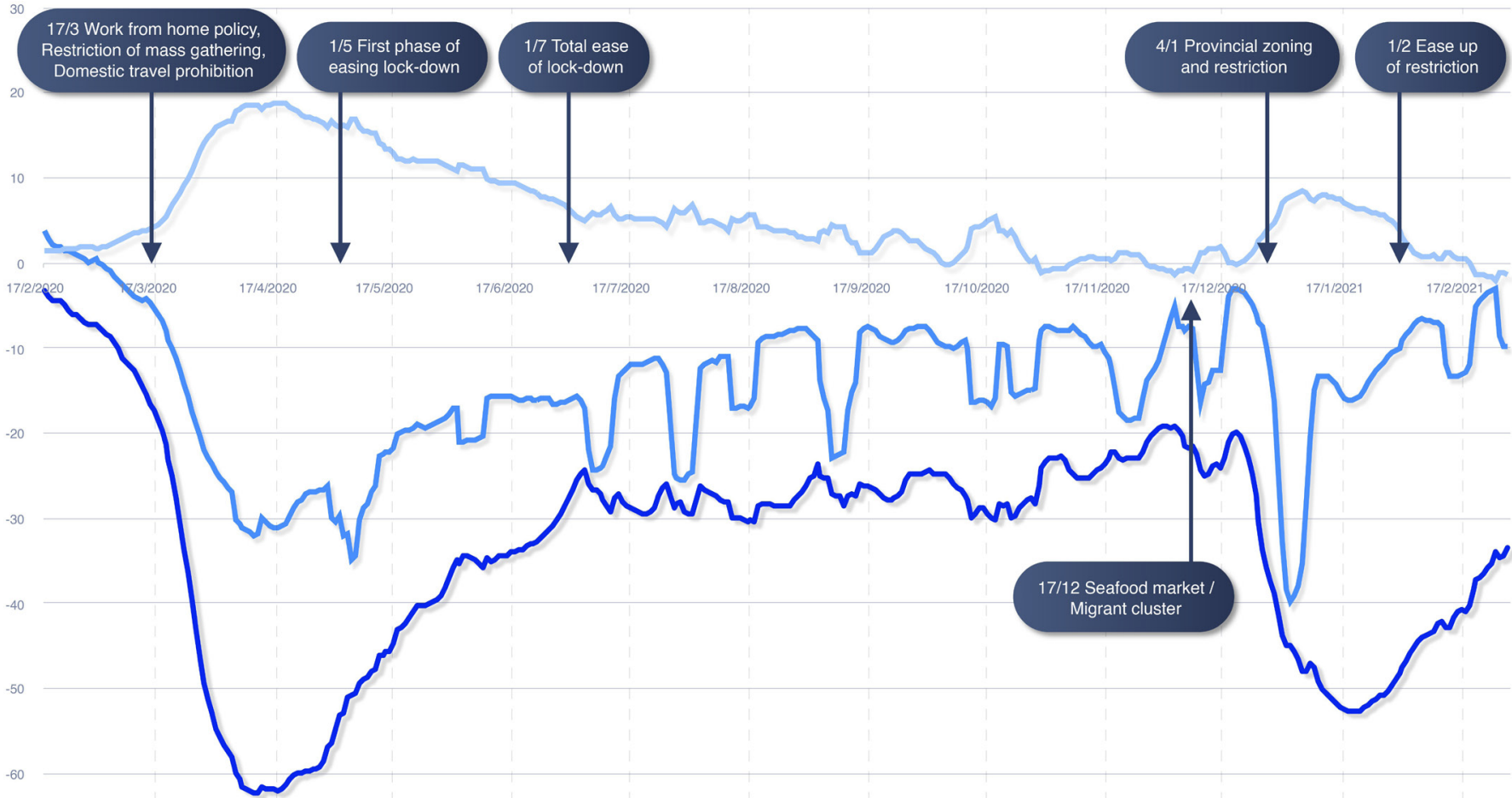

\section{Transit stations Workplaces Residential}

Figure 4 Google mobility data and social measures, February 2020-2021.

\section{LEARNING FROM FIRST WAVE EXPERIENCES TO APPLY TO SECOND WAVE RESPONSES}

Although Thailand relies on migrant workers, mostly from Myanmar and in particular the fishery industry, the government failed to establish active surveillance in migrant communities. Many migrants entered Thailand illegally through the 2400 kilometre-long porous natural border between Thailand and Myanmar and possibly through labour trafficking. ${ }^{12}$ Myanmar's epidemic peaked in November and December 2020. ${ }^{13}$ Another lesson was that Thailand population felt complacency due to the small number of cases, which resulted in reduced face mask coverage, the lowest level of which was 77\% in September 2020.

Asymptomatic infections in migrant workers in a wholesale seafood market in Samut Sakhon triggered the massive second wave. The market serves customers nationwide; retailers from other provinces came to purchase goods, were infected and transmitted the virus back in their provinces. A cluster was identified through contact tracing and active case finding starting from an index case in a hospital. In a single day, more than 500 cases were detected, and $90 \%$ were migrant workers. This means that transmission circulated in the community for at least three to four generations before detection. Additionally, the WHO has classified COVID-19 into seven different clades: namely S, V, L, G, GH, GR and O (others).${ }^{14}$ The GH clades, which widely spread in India and Myanmar, were confirmed by the Department of
Medical Science as responsible for the outbreak in this province. ${ }^{15}$

At the beginning of the second wave, the reproductive number of 35 was much greater than the 9 in the first wave. A few reasons explain this large reproductive number. Most migrant workers $(86 \%)$ were asymptomatic and therefore the virus spread unnoticeably. ${ }^{16}$ Without the use of face masks as source control among migrant workers and as primary protection for market customers, the virus spread quickly. ${ }^{17}$ Large transmissions occurred among migrant workers due to overcrowded dormitories and the market itself, which accelerated the number of infections. Due to the very high caseload and identifiable hotspot, the main disease control strategy in Samut Sakhon shifted from individual contact tracing to active case finding by testing everyone in the suspected factories or construction sites. Individual contact tracing was timeconsuming through single interviews of cases to identify their high-risk contacts, and their phone numbers and home addresses. Active case finding then became the more cost-effective and timely intervention, and was only applied in areas with a high prevalence of infections. However, contact tracing still played an effective role in low-prevalence provinces. ${ }^{18}$

The second wave response, instead of a nationwide lockdown, categorised provinces into three different levels depending on the outbreak situation and risk. This included locking down five hotspot provinces to facilitate active case findings until all the suspected population 


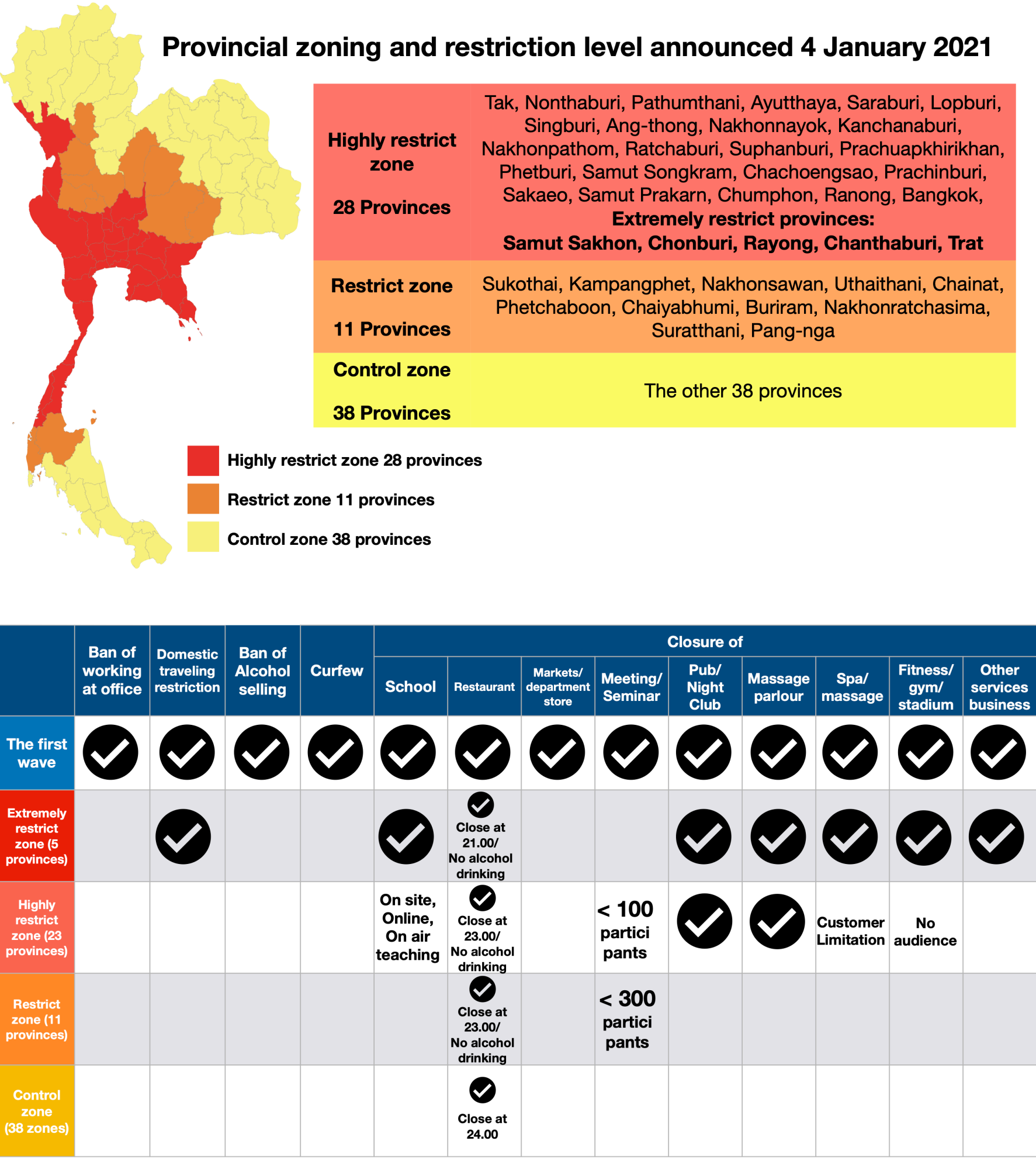

Figure 5 Provincial zoning and restriction level announced 4 January 2021 and comparison of social measures used in the first wave and specific zones during the second wave. Five extremely restrict provinces are Samut Sakhon, Chonburi, Rayong, Chanthaburi and Trat.

groups had been fully investigated (see figure 5). Within the sealed areas, workers were allowed to travel between their dormitories and the factory, which encouraged economic activity to continue and gained the employers' support. The waiver of legal action against undocumented migrants ensured their cooperation to show up for testing. In the active case findings, a standard individual RT-PCR test was replaced with a five-sample pooled saliva test for cost-savings in relatively lower prevalence areas around the hotspot. ${ }^{19}$ A study shows that in areas of prevalence of $>3 \%$, a five-sample pooled saliva test requires the least overall number of RT-PCR tests. ${ }^{20}$ Saliva 
test (pooled and non-pooled) in Samut Sakhon province between 26 December 2020 and 28 February 2021 showed that of the total 95078 tests, $8.5 \%$ (8074 tests) were positive. ${ }^{21}$

After the second wave outbreak was announced, the population's preventive behaviour significantly improved and their mobility decreased. Schools in high-infection areas were closed in January 2021. Although domestic travel restrictions were not applied nationwide, the downward trend of people's movement to transit stations and workplaces in January 2021 was similar to that of April 2020.

Migrant health workers and volunteers, trained by $\mathrm{MOPH}$ to support health services in migrant communities, were fully deployed. ${ }^{22}{ }^{23}$ Over 3000 field hospital beds were immediately set up in temples, military camps and large warehouses, fully supported by the Provincial Chamber of Commerce and Provincial Chapter of Federation of Thai Industries. Field hospitals accommodated asymptomatic cases while moderate to severe cases were treated in hospitals. Human resources were pulled from other provinces, both from MOPH and outside.

Although the second wave had a much higher caseload, the case fatality rate was $0.11 \%$, much lower than $1.46 \%$ in the first wave. More cases were among young healthy working-age people and were mostly asymptomatic. ${ }^{24}$

\section{MULTILEVEL GOVERNANCE OF COVID-19 RESPONSES}

The CCSA, established in March 2020, continued its proactive work with daily briefings televised nationwide to report the epidemiological situation and advocate the need for people's adherence to face mask coverage and hand hygiene. ${ }^{25}$ The MOPH-EOC met daily including at weekends to monitor and provide advice and support. MOPH-EOC meetings also held 'live briefings' with provincial chief medical officers in affected provinces. In the second wave, the principle of containment shifted from a nationwide approach to a more strategically selective and targeted approach. This meant zoning provinces into red, orange, and yellow according to weekly new cases per million of over 15 , between 5 and 15 , and less than 5, respectively, and differentiated interventions according to the zone. ${ }^{26}$

\section{KEY SUCCESS FACTORS, REMAINING CHALLENGES AND RESPONSES \\ Key success factors}

The legacy of surveillance and preparedness capacity over years played a critical role. Thailand ranks sixth in the Global Health Security Index as a result of four decades of investment in surveillance and preparedness and integration of these capacities into district health systems. ${ }^{27}$ The district level SRRT preparedness and response capacity was gradually strengthened and sustained through regular outbreak investigations and responses in the community to diseases such as dengue, meningococcemia, hand, foot and mouth disease, and rabies. SRRT capacity through regular drills ensured the SRRT was ready for major epidemics such as the highly pathogenic avian influenza in $2004,{ }^{28}$ SARS in $2003^{29}$ and Middle East respiratory syndrome coronavirus in $2015 .^{30}$ Field epidemiologist training since 1980 has resulted in the critical mass of epidemiological capacity in Thailand. ${ }^{31}$ However, even after four decades of training, the number of epidemiologists has reached only half the target of 1 epidemiologist per 200000 people as recommended by the WHO. ${ }^{32}$ Thailand's surveillance capacity to detect variants of concern, notably B.1.1.7 and B.1.351 variants, has been strengthened through ensuring international travellers stay in state quarantine. ${ }^{33-35}$

In a normal situation, VHVs support the screening of diabetes and hypertension in their community, mobilise community awareness of dengue prevention and control, and support health workers during home visits to homebound and bedridden patients. ${ }^{36}$ During the avian influenza epidemic in 2004, these volunteers monitored any abnormal number of deaths in poultry and free-grazing ducks and alerted animal and human health authorities to investigate. This early detection and control at source helped the rapid containment of avian influenza. ${ }^{37} 38$

During the COVID-19 pandemic, the VHVs contributed significantly to support surveillance and advocated personal prevention measures. ${ }^{3}{ }^{39-41}$ The volunteers greatly supported SRRT to identify contact cases for investigation. In Samut Sakhon province, migrant health workers and health volunteers, mostly Myanmar nationals, played a significant role to support contact tracing as they know the community and speak the same dialect. $^{23}$

Universal Health Coverage facilitated full access to quality COVID-19 services without copayment. Early hospital admission of moderate and severe cases resulted in the low mortality rate. The government approved a significant budget to MOPH for scaling up certified PCR laboratory tests nationwide and payment for tests for all nationals and non-nationals. All district and provincial hospitals were mandated to detect, test and conduct outbreak investigations and responses. ${ }^{42}$

\section{Remaining challenges}

The porous land border and fragile political situation in Myanmar are the main causes of migrant influx into Thailand, despite border police and army patrol push back. ${ }^{43}$

The geographical challenge is exacerbated by unresolved labour trafficking activities. Thailand lacks a clear labour policy for migrant workers despite critical labour shortages in some sectors, which provides a fertile ground for corruption and continued labour trafficking. ${ }^{44}$ Despite the government's increased efforts, corruption and official complicity facilitates trafficking and continues to impede anti-trafficking efforts. ${ }^{45}$ Both factors contribute to a substantial number of undocumented migrants entering the country where infections are not captured by the quarantine system. 
An additional problem is that undocumented migrant workers do not show up for tests for fear of legal action and deportation, despite awareness campaigns by migrant health workers and migrant health volunteers in Samut Sakhon province. Similarly, employers who hire undocumented migrants fear prosecution themselves. Policy incoherence between national security and pandemic containment complicated Thailand's COVID-19 response.

\section{Responses to challenges}

Labour trafficking could be solved by policy coherence across government sectors: labour, national security and health, and zero tolerance to corruption. Responses to large clusters of COVID-19 applied active case findings with five-sample pooled saliva tests in suspected factories and the lockdown of specific localities. At the operational level, the suspension of prosecution to undocumented migrants and their employers for pandemic containment was adopted. ${ }^{46}$

\section{CONCLUSION}

The immediate public health measures and national lockdown in the first wave resulted in no local transmission after May 2020 at the expense of the economy, leading to catastrophic economic consequences and government financial rescue programmes. Small numbers of cases then encouraged population complacency and more relaxed personal prevention behaviour. Undocumented migrants through labour trafficking brought asymptomatic infections and triggered a second wave larger than the first one. Structural responses from the first wave, notably nationwide scale-up of PCR laboratory services, negative pressure rooms and stockpiling of personal protective equipment, are legacy for responses in the second wave. Agile and adaptive responses were adopted in the second wave, especially active case finding, use of pooled saliva tests and maintaining economic activities through targeted lockdown of affected localities. ${ }^{47}$

Lessons can be drawn and shared with other countries. First, timely implementation of public health and social measures through harmonised single command resulted in successful containment of COVID-19. Second, scaled up capacity of, notably, laboratory tests and the stockpiling of essential medical resources are the foundations for responding to unpredictable large and different disease outbreaks. Third, agile and adaptive responses are critical to respond to the different sizes and nature of transmissions. Finally, targeted lockdown and active case findings are adaptive responses to maintain the economic activity and increase effectiveness of case identification.

Acknowledgements This publication has been supported by the German Federal Ministry of Health (BMG) COVID-19 research and development funding to the WHO.

Contributors All authors conceived and framed the manuscript. VT (the guarantor of the paper) provided concept and support to the manuscript. All the authors contributed to the drafting of the manuscript and approved the final version prior to submission.
Funding This study was funded by WHO, Bundesministerium für Gesundheit.

Map disclaimer The inclusion of any map (including the depiction of any boundaries therein), or of any geographic or locational reference, does not imply the expression of any opinion whatsoever on the part of BMJ concerning the legal status of any country, territory, jurisdiction or area or of its authorities. Any such expression remains solely that of the relevant source and is not endorsed by BMJ. Maps are provided without any warranty of any kind, either express or implied.

Competing interests None declared.

Patient and public involvement Patients and/or the public were not involved in the design, or conduct, or reporting, or dissemination plans of this research.

Patient consent for publication Not required.

Provenance and peer review Not commissioned; externally peer reviewed.

Data availability statement (6) Data may be obtained from a third party and are not publicly available

Open access This is an open access article distributed in accordance with the Creative Commons Attribution Non Commercial (CC BY-NC 4.0) license, which permits others to distribute, remix, adapt, build upon this work non-commercially, and license their derivative works on different terms, provided the original work is properly cited, appropriate credit is given, any changes made indicated, and the use is non-commercial. See: http://creativecommons.org/licenses/by-nc/4.0/.

ORCID iD

Nattadhanai Rajatanavin http://orcid.org/0000-0001-6505-7911

\section{REFERENCES}

1 World Health Organization Country Office Thailand. Thailand COVID-19 situation report 1st May 2020. Available: https://www. who.int/docs/default-source/searo/thailand/2020-05-01-tha-sitrep69-covid19-th.pdf?sfvrsn=11dff472_2 [Accessed 7 Jun 2021].

2 Marome W, Shaw R. COVID-19 response in Thailand and its implications on future preparedness. Int J Environ Res Public Health 2021:18:1089-11.

3 Issac A, Radhakrishnan RV, Vijay VR, et al. An examination of Thailand's health care system and strategies during the management of the COVID-19 pandemic. J Glob Health 2021;11.

4 Ministry of Public Health Thailand. Thailand national COVID-19 treatment guideline. Available: https://covid19.dms.go.th/backend/ Content/Content_Flle/Bandner_(Big)/Attach/25640507102416AM_ CPG_COVID_v.14_n_20210506.2.pdf [Accessed 4 Jun 2021].

5 Ministry of Public Health Thailand. Laboratory SAR-COV2 detection network. Available: https://service.dmsc.moph.go.th/labscovid19/ indexen.php [Accessed 6 Mar 2021].

6 Ministry of Public Health Thailand. Outbreak surveillance: Situation Awareness Team \& Joint Investigation Team Standard. 107. Available: http://www.pngo.moph.go.th/pngo/images/meeting2/ 620621/2406-6.pdf [Accessed 6 Mar 2021].

7 World Health Organization. Thailand's 1 million village health volunteers - "unsung heroes" - are helping guard communities nationwide from COVID-19, 2020. Available: https://www.who.int/ thailand/news/feature-stories/detail/thailands-1-million-villagehealth-volunteers-unsung-heroes-are-helping-guard-communitiesnationwide-from-covid-19 [Accessed 12 Apr 2021].

8 Howard J, Huang A, Li Z, et al. An evidence review of face masks against COVID-19. Proc Natl Acad Sci U S A 2021;118:e2014564118.

9 Our World in Data. Google community mobility trends. Available: https://ourworldindata.org/covid-google-mobility-trends [Accessed 15 Mar 2021].

10 Ministry of Public Health Thailand. Sentinel surveillance guideline, 2020. Available: https://ddc.moph.go.th/viralpneumonia/file/g_srrt/ g_srrt_target_group.pdf

11 Oxford Policy Management and The United Nation Thailand. Social impact assessment of COVID-19 in Thailand. 2020;186. Available: https://www.unicef.org/thailand/media/5071/file/Social Impact Assessment of COVID-19 in Thailand.pdf\#page $=132$

12 Royal Thai Government. Interception of Undocumented migrant guideline for prevention of COVID-19 7th December 2020. Available: http://www.ratchakitcha.soc.go.th/DATA/PDF/2563/E/286/T_0021. PDF [Accessed 7 Jun 2021]

13 Our World in Data. COVID-19 Data Explorer (Myanmar) - Our World in Data. Available: https://ourworldindata.org/explorers/ coronavirus-data-explorer?zoomToSelection=true\&time=40.latest $\&$ pickerSort=desc\&pickerMetric=new_cases_smoothed_per_million\& 
Metric $=$ Confirmed + cases\&Interval $=\mathrm{New}+$ per+day\&Relative+to + Population=false\&Align+outbreaks=false \& [Accessed $12 \mathrm{Apr}$ 2021].

14 Hamed SM, Elkhatib WF, Khairalla AS, et al. Global dynamics of SARS-CoV-2 clades and their relation to COVID-19 epidemiology. Sci Rep 2021;11:8435.

15 Ministry of Public Health Thailand. Thailand COVID-19 situation report 23rd December 2020. Available: https://ddc.moph.go. th/viralpneumonia/file/situation/situation-no355-231263n.pdf [Accessed 10 Jun 2021].

16 Ministry of Public Health Thailand. Samutsakorn COVID-19 Investigation December 2020 - January 2021.

17 Esposito S, Principi N, Leung CC, et al. Universal use of face masks for success against COVID-19: evidence and implications for prevention policies. Eur Respir J 2020;55 doi:10.1183/13993003.01260-2020. [Epub ahead of print: 1806 2020].

18 Ministry of Public Health Thailand. COVID-19 Outbreak Surveillance \& Investigation guideline. Available: https://ddc.moph.go.th/ viralpneumonia/file/g_srrt/g_srrt_150563.pdf [Accessed 10 Jun 2021].

19 Wacharapluesadee S, Kaewpom T, Ampoot W, et al. Evaluating the efficiency of specimen pooling for PCR-based detection of COVID-19. J Med Virol 2020;92:2193-9.

20 Watkins AE, Fenichel EP, Weinberger DM. Pooling saliva to increase SARS-CoV-2 testing capacity. medRxiv.

21 Ministry of Public Health Thailand. Active case finding test result (Samut Sakhon) 2020.

22 Pocock N, Suphanchaimat R. Moving towards culturally competent, migrant-inclusive health systems: a comparative study of Malaysia and Thailand. New Delhi, 2021.

23 Kosiyaporn $\mathrm{H}$, Julchoo S, Sinam $\mathrm{P}$, et al. Health literacy and its related determinants in migrant health workers and migrant health volunteers: a case study of Thailand, 2019. Int J Environ Res Public Health 2020;17:2105.

24 Royal Thai Government. Emergency operation center briefing 1 March 2021, 2021. Available: https://media.thaigov.go.th/uploads/ public_img/source/010364.pdf [Accessed 4 Jun 2021].

25 Royal Thai Government. Establishment of centre for COVID-19 situation administration (CcsA) 12th March 2020. Available: https:// media.thaigov.go.th/uploads/document/66/2020/03/pdf/Doc_ 20200314193011000000.pdf [Accessed 26 Feb 2021].

26 Ministry of Public Health Thailand. COVID-19 outbreak zoning criteria 24th December 2020. Available: https://ddc.moph.go. th/viralpneumonia/file/im_commands/im_commands12_1.pdf [Accessed 10 Jun 2021].

27 John Hopkins Univerity. 2019 global health security index. Available: https://www.ghsindex.org [Accessed 25 Feb 2021].

28 Tiensin T, Chaitaweesub P, Songserm T, et al. Highly pathogenic avian influenza H5N1, Thailand, 2004. Emerg Infect Dis 2005;11:1664-72.

29 ChaovChaovavanich A, Wongsawat J, Dowell S. Early containment of severe acute respiratory syndrome (SARS); experience from Bamrasnaradura Institute, Thailand. J Med Assoc Thail 2004;87:1182.
30 Plipat T, Buathong R, Wacharapluesadee S, et al. Imported case of middle East respiratory syndrome coronavirus (MERS-CoV) infection from Oman to Thailand, June 2015. Eurosurveillance2017;22:30598.

31 Jones DS, Dicker RC, Fontaine RE, et al. Building global epidemiology and response capacity with field epidemiology training programs. Emerg Infect Dis 2017;23:S158-65.

32 Williams SG, Fontaine RE, Turcios Ruiz RM, et al. One field epidemiologist per 200,000 population: lessons learned from implementing a global public health workforce target. Health Secur 2020;18:S-113-S-118.

33 Mahase E. Covid-19: what have we learnt about the new variant in the UK? BMJ 2020;371:m4944.

34 Ministry of Public Health Thailand. Daily news briefing 3rd January 2021. Available: https://pr.moph.go.th/_WEBADMIN/uploads/attfiles/ 5zpwtso4hg4c0kwwo.pdf [Accessed 7 Jun 2021].

35 Royal Thai Government. Emergency operation center briefing 15th February 2021. Available: https://media.thaigov.go.th/uploads/ public img/source/150264.pdf [Accessed 7 Jun 2021].

36 Kowitt SD, Emmerling D, Fisher EB, et al. Community health workers as agents of health promotion: analyzing Thailand's village health volunteer program. J Community Health 2015;40:780-8.

37 Guan Y, Chen H, Li KS, et al. A model to control the epidemic of H5N1 influenza at the source. BMC Infect Dis 2007;7:1-8.

38 Olsen SJ, Ungchusak K, Birmingham M, et al. Surveillance for avian influenza in human beings in Thailand. Lancet Infect Dis 2006:6:757-8.

39 Vicerra PMM. Knowledge-Behavior gap on COVID-19 among older people in rural Thailand. Gerontol Geriatr Med 2021;7:233372142199720.

40 Tejativaddhana P, Suriyawongpaisal W, Kasemsup V. The roles of village health volunteers: COVID-19 prevention and control in Thailand. Asia Pacific J Heal Manag 2020;15:477.

41 Kaweenuttayanon N, Pattanarattanamolee R, Sorncha N, et al. Community surveillance of COVID-19 by village health volunteers, Thailand. Bull World Health Organ 2021;99:393-7.

42 Ministry of Public Health Thailand. Thailand's Experience in the COVID-19 Response. Available: https://ddc.moph.go.th/ viralpneumonia/eng/file/pub_doc/LDoc9.pdf [Accessed 10 Jun 2021].

43 United Nations. Security Council press statement on situation in Myanmar. Available: https://www.un.org/press/en/2021/sc14430. doc.htm [Accessed 7 Jun 2021]

44 Suphanchaimat R, Putthasri W, Prakongsai P, et al. Evolution and complexity of government policies to protect the health of undocumented/illegal migrants in Thailand - the unsolved challenges. Risk Manag Healthc Policy 2017;10:49-62.

45 United States Department of State. 2020 trafficking in persons report: Thailand. Available: https://www.state.gov/reports/2020 trafficking-in-persons-report/thailand/ [Accessed 10 Jun 2021].

46 Royal Thai Government. Amnesty of Undocumented migrants annoucement 30th December 2020. Available: http://www. ratchakitcha.soc.go.th/DATA/PDF/2563/E/305/T_0012.PDF [Accessed 11 Jun 2021].

47 Janssen $\mathrm{M}$, van der Voort $\mathrm{H}$. Agile and adaptive governance in crisis response: lessons from the COVID-19 pandemic. Int $J$ Inf Manage 2020;55:102180. 